Cakrawala Dini: Jurnal Pendidikan Anak Usia Dini | p-ISSN 2087-1317 | e-ISSN 2621-8321 Vol. II. No.2 November 2020 | Hal 150-154

\title{
PENGGUNAAN TEKNOLOGI 3 DIMENSI SEBAGAI METODE PEMBELAJARAN GEOMETRI PADA ANAK USIA 5 - 6 TAHUN
}

\author{
Khusnul Khotimah ${ }^{1}$ \\ ${ }^{1}$ Universitas Sebelas Maret
}

\begin{abstract}
Geometry is an important field for life and need to be teaching as early as possible so that children's understanding ability about space and shape can get better. Old learning geometry methode only using paper and pencil while now as techonologies growing up so fast, teacher and school start using technology as a media learning for geometry. By using technology, such as; virtual reality, dynamics geometry software, etc, children can more develop and explore their geometric ability and get to know more about geometry. Plus, children around age 5- years old usually learning something through concrete so that's why we need techonology as a media to make geometric learning more realistic so that children can develop their cognitive ability, especially in geometry field. This is qualitative study and using literature study as a collecting data methode. So, the conclusion is that by using technology as a geometry learning media is really help for children aged 5-6 years old to get to more understand about geometry.
\end{abstract}

Keyword: Geometry, Technology, 5-6 years old.

\begin{abstract}
Abstrak: Geometri adalah bidang yang penting bagi kehidupan dan perlu diajarkan sedini mungkin agar tingkat kemampuan anak untuk mengenal ruang maupun bentuk menjadi lebih baik. Pembelajaran geometri kuno menggunakan metode kertas dan pensil, tetapi seiring perkembangan zaman teknologi digunakan sebagai media belajar geometri dan memberikan hasil yang lebih baik dari sekedar kertas. Melalui penggunaan media Virtual Reality, software Dynamics Geometry dan lain sebagainya, anak lebih mampu mengembangkan dan mengeksplor kemampuannya untuk mengenal geometri. Terlebih anak usia 5-6 tahun yang mempelajari suatu secara konkret maka diperlukan teknologi yang mendukung untuk perkembangan kemampuan kognitif mereka, terutama kemampuan geometris. Penelitian ini merupakan penelitian kualitatif dengan menggunakan studi pustaka sebagai alat pengumpulan data. Didapatkan kesimpulan bahwa pemanfaatan teknologi dalam pembelajaran geometri bagi anak usia 5-6 tahun sangat membantu anak untuk mudah memahami suatu bentuk bangun datar.
\end{abstract}

Kata Kunci: Geometri, Teknologi, 5-6 tahun

'Universitas Sebelas Maret, Email: khusnul.khatimah14.kk国gmail.com

150 Cakrawala Dini: Vol. II No. 2, November ZUZO 


\section{PENDAHULUAN}

Geometri adalah bidang yang penting dalam ranah ilmu matematika yang mana bidang ini mempelajari tentang ruang (Galitskaya \& Drigas, 2020). Pembelajaran geometri diberikan kepada anak sejak anak masuk dunia sekolah, pemberian bekal ini bermanfaat agar anak lebih memahami dan mengenali lingkungan tempat mereka tinggal(Crompton, Grant, and Shraim 2018). Pembelajaran geometri anak usia dini sering kali tidak efektif bagi anak, pemberian materi belajar hanya menggunakan alat - alat belajar berupa gambar atau benda - benda di sekitar anak, sehingga terkadang anak mengalami kesulitan untuk membedakan ciri - ciri satu bentuk datar dengan bentuk lainnya. Salah satu cara untuk mengatasi kesulitan anak menganalisa bentuk bangun datar adalah dengan menggunakan teknologi 3 dimensi, teknologi ini mengajak anak untuk melihat bentuk bangun datar secara 3 dimensi menggunakan alat bantu bernama Virtual Reality, dengan menggunakan bentuk 3 dimensi yang notabene terlihat lebih nyata anak di harap dapat membedakan bentuk bangun datar lebih tepat.

Menurut Van Hiele, terdapat beberapa tahapan dalam perkembangan berfikir geometri, yaitu;

a. Level 1 (Visualisasi); pada tahap ini anak dapat membayangkan mengenai bentuk suatu bangun datar berdasar pada visualisasi bentuk yang mereka lihat pada awalnya.

b. Level 2 (Analisis); pada tahap ini anak hanya mampu untuk mengingat ciri ciri dari bangun datar, terutama ciri ciri penting.

c. Level 3 (Abstraksi); Anak mampu merumuskan pengertian sederhana bentuk datar secara berjenjang, berdasar pada ciri - ciri khusus yang dia ingat dan mampu mendeskripsikan nya.

d. Level 4 (Deduksi); pada tahap ini anak mampu untuk membedakan antar bangun datar dan mampu memberikan bukti bahwa perkataannya benar.

e. Level 5 (Ketegasan); pada tahap ini anak sudah mampu membedakan antar bangun datar dengan jelas dan tepat.

Berdasar pada penelitian tentang "Understanding of selected geometric concepts by pupils of pre-primary and primary level Education" (Zilkova 2017) menjelaskan bahwa anak - anak masih membedakan antara satu bentuk dengan bentuk lain secara holistik sehingga terkadang masih melakukan kesalahan saat mengidentifikasi setiap bentuk. Berdasar pada teori Van Heile anak usia dini berada pada Level 1 dan level 2 (Zilkova 2017). Pada tahap ini, penyajian materi belajar geometri haruslah senyata mungkin agar anak tidak merasa kebingungan dalam membedakan satu bangun datar dengan lainnya. Tidak diragukan lagi, lingkungan yang mendukung, kesempatan anak dan alat belajar yang mumpuni dapat mempengaruhi perkembangan mereka dengan baik (ASLAN 2017).

Penelitian sebelumnya berjudul "Geometry teaching experience in virtual reality with NeoTrie VR" (Rodr 2020), permainan Virtual Reality ini diisi dengan tugas - tugas yang berkaitan dengan geometri seperti menggambar, membuat bentuk dan menggambar bebas. Hasil dari penelitian ini menjelaskan bahwa dengan menggunakan teknologi NeoTrie Virtual Reality dapat membantu anak usia 11-15 tahun untuk lebih cepat memahami suatu bentuk dan lebih cepat mengerjakan tugas - tugas geometri.

Berdasar pada kedua penelitian di atas, pada penelitian yang berjudul "Understanding of selected geometric concepts by pupils of pre-primary and primary level Education"(Zilkova 2017), hanya menjelaskan mengenai bagaimana anak usia dini kesulitan untuk membedakan bentuk - bentuk dan tidak menjelaskan secara rinci solusi apa yang harus pendidik lakukan untuk mengatasi hal tersebut. Sedangkan, penelitian 
"Geometry teaching experience in virtual reality with NeoTrie VR"(Rodr 2020), menggunakan teknologi tersebut dengan partisipan anak berusia 11 - 15 tahun dan tidak menjelaskan secara rinci apakah teknologi tersebut dapat bermanfaat juga untuk anak dengan tingkat usia yang berbeda. Oleh karena itu, penulisan artikel ini diharapkan dapat menggabungkan kedua penelitian di atas dan dapat menemukan apakah teknologi 3 dimensi dan penggunaan Virtual Reality dapat memberi dampak signifikan bagi kemampuan anak usia dini untuk memahami suatu bentuk dengan mudah dan tepat.

\section{METODOLOGI PENELITIAN}

Penelitian berbentuk penelitian kualitatif dan pengumpulan data menggunakan metode studi kepustakaan. Menggunakan data - data dari penelitian sebelumnya untuk kemudian disimpulkan menjadi satu dan menjawab permasalahan yang diangkat di penelitian ini.

\section{HASIL PENELITIAN DAN PEMBAHASAN}

Geometri adalah bidang yang penting di dalam matematika yang mana berguna untuk memahami mengenai ruang (Galitskaya and Drigas 2020). Geometri membantu murid untuk menganalisis dan menjelaskan mengenai dunia (Galitskaya and Drigas 2020), seperti mengenal kan dan menjelaskan mengenai; bentuk, ruang, jarak, bangun datar, bangun ruang dan lain sebagainya, yang mana hal tersebut merupakan elemen yang ada di dunia. Pembelajaran geometri diajarkan kepada anak mulai dari anak memasuki usia kanak - kanak, mulai dari pendidikan anak usia dini sampai universitas. Pada pendidikan anak usia dini, anak diajarkan untuk mengenal bentuk - bentuk geometris sesuai dengan perkembangan usianya. Menurut Permendikbud Nomor 58 tahun 2009, kemampuan geometri anak usia 2-3 tahun adalah mengenal bentuk lingkaran dan persegi, untuk anak usia 3-4 tahun adalah mengenal bentuk persegi, persegi panjang, segitiga dan lingkaran. Sedangkan untuk anak usia 5-6 tahun adalah mampu mengenal 6 macam bentuk, yaitu; persegi, persegi panjang, segitiga, lingkaran, trapesium dan belah ketupat.

Media pembelajaran yang digunakan guru pada umumnya antara lain; buku, gambar, mainan dan buku ilustrasi. Fakta nya, berdasar pada penelitian yang dilakukan oleh Melek Merve YILMAZ GENC, Aysegul AKINCI COSGUN dan Sengul PALA, sekelompok peneliti dari Turki yang meneliti mengenai seberapa efektif penggunaan media buku ilustrasi atau text book dalam mengajarkan matematika kepada anak, hasil yang diberikan bahwasanya buku ilustrasi bergambar dinilai efektif untuk mengajarkan matematika kepada anak usia dini sebab dengan penggunaan media ini anak akan lebih mudah memahami konsep mengenai besar-kecil, banyak-sedikit, panjangpendek dan juga anak lebih mudah untuk memvisualisasikan kasus - kasus matematika di dunia nyata, sebab cerita yang disampaikan di dalam buku ilustrasi adalah cerita yang berkaitan dengan dunia nyata. Tetapi, penggunaan media ini lebih mengacu kepada pengajaran matematika dalam bidang nominal dan bidang hitungan, tidak berlaku untuk bidang geometri.

Seiring dengan berkembangnya zaman, pendidikan tidak hanya menggunakan kertas dan pensil sebagai media pembelajaran, penemuan dan teknologi baru banyak diciptakan untuk memudahkan murid memahami suatu materi belajar. Salah satunya adalah pengembangan media belajar geometri. Pengembangan media belajar geometri berarti masuknya teknologi maupun hal hal atau metode baru di dalam belajar geometri, yang nantinya akan memudahkan siswa untuk lebih mudah mempelajari nya. Pembelajaran geometri 
menggunakan teknologi memiliki 3 manfaat menurut Van de Walle (1998), yaitu; (1) Mengurangi waktu anak untuk menginterpretasikan dan menyelesaikan tugas matematika, (2) anak dapat memahami konsep yang berbeda, seperti; grafik 3 dimensi, (3) matematika menjadi lebih sederhana dan lebih mudah (Galitskaya and Drigas 2020). Jenis teknologi yang dapat digunakan dalam pembelajaran geometri ada dua macam yaitu hardware (perangkat keras) dan software (perangkat lunak). Perangkat keras antara lain; komputer, telepon seluler, VR (Virtual Reality), tablet layar sentuh dan perangkat teknologi lainnya. Selain itu, perangkat lunak nya antara lain; Dynamic Geometry Environments (DGEs, termasuk juga 3D Dynamic Geometry Software) dan Logo-based Environment (Crompton et al. 2018). Dua software tersebut memiliki tools/perangkat gambar geometri yang berbeda, DGE merupakan perangkat lunak geometri yang dikembangkan pada tahun 1980 dengan spesifikasi dapat membuat garis, titik, lingkaran dan juga membuat bentuk figur. Kemudian pada tahun 2000 an sofware ini dikembangkan lagi sehingga dapat membuat benda bergerak dan dapat dilihat dari berbagai sudut (3 dimensi). Selanjutnya terdapat software bernama Logo yaitu software yang memiliki basic pemograman bahasa seperti Logo-based Turtle Geometry dan berhubungan dengan Microworlds (Crompton et al. 2018). Software ini memiliki cara kerja yaitu di dalam kerja terdapat figur kura - kura yang akan membentuk suatu bangun ruang atau datar dengan diperintah menggunakan suara. Melalui software ini anak - anak dapat belajar dan menjelajahi permainan membangun suatu benda. Software dari Logo ini kebanyakan digunakan untuk pembelajaran menggunakan Virtual Reality/VR, suatu alat pembelajaran yang menghadirkan bentuk 3 dimensi secara nyata seolah - olah anak sedang benar benar melihatnya di dunia nyata. Selain kedua software di atas terdapat satu software baru yang diluncurkan pada tahun 2018 bernama NeoTrie VR/Neotrie adalah suatu paket software untuk perangkat Virtual Reality yang dikembangkan oleh Virtual Dor (Universitas Almeria di Spanyol) yang mana software ini dapat membantu anak untuk membuat, memanipulasi dan berinteraksi dengan objek geometri 3 dimensi dan model 3 dimensi lainnya. Dengan satuan perangkat Neotrie VR anak dapat membuat bentuk - bentuk 3 dimensi yang mereka inginkan dan juga dapat mewarnai bentuk - bentuk tersebut.

Hasil penelitian dari jurnal yang berjudul "Geometry teaching experience in virtual reality with NeoTrie VR" menyebutkan bahwa penggunaan Neotrie $V R$ dapat membantu anak untuk menjawab permasalahan geometri secara lebih mudah, anak lebih dapat untuk memahami konsep dari area atau bidang dari suatu figur, menambah kemampuan mereka untuk mengimajinasikan bentuk spasial dan meningkatkan kreativitas.

Pada usia dini, anak cenderung untuk merepresentasikan bentuk bangun datar sebagai suatu benda yang familiar di sekitarnya. Hal ini muncul di dalam penelitian yang dilakukan di turki berjudul "Children's Geometric Understanding through Digital Activities: The Case of Basic Geometric Shapes" (Özçakır, Konca, and Arıkan 2019). Penelitian ini meneliti mengenai efektivitas penggunaan teknologi dalam mengajarkan geometri kepada anak. Partisipan yang dipilih sebagai sampel penelitian adalah anak usia dini berumur 5 tahun. Mereka diajak untuk bermain sembari belajar mengenai geometri menggunakan tablet layar sentuh dan software bernama Geogebra dari aplikasi Dynamic Geometry. Kegiatan geometri yang dilakukan tidak hanya menggambar tetapi juga; menjelaskan bentuk, mewarnai bentuk, mewarnai bentuk yang sama dengan warna senada, menyebutkan nama - nama bentuk, menjelaskan ciri - 
ciri bentuk bangun datar yang ada, mewarnai bentuk bangun datar yang sama dan mencocokan bentuk benda - benda di sekitar rumah dengan gambar bangun datar yang ada.

Pada penelitian ini, peneliti menemukan beberapa hasil, yaitu; 1 . Pembelajaran secara digital membantu anak untuk meningkatkan kemampuan kognitif level nya dalam hal geometri, 2. Anak - anak memiliki cara mereka sendiri untuk menjelaskan mengenai suatu bentuk, mereka cenderung untuk menyamakan bentuk bangun datar dengan bentuk hal - hal familiar di sekitar mereka, 3. Aktivitas digital memiliki banyak orientasi bentuk bangun datar (dapat dilihat secara 3 dimensi) yang mana hal ini kemudian mampu membuat anak paham konsep mengenai bentuk geometri dengan wujud aslinya di dunia nyata, lalu yang ke empat aktivitas digital ini membantu anak untuk meningkatkan kemampuan mereka dalam membuat keputusan dan membuat mereka meningkatkan sisi sosial mereka dengan cara membantu teman yang lain saat tengah kesusahan.

\section{KESIMPULAN}

Anak berusia $5-6$ tahun berada pada tahap melihat suatu benda atau bangun datar secara konkret dan geometri merupakan suatu bidang yang membutuhkan visualisasi nyata dibandingkan hanya menggunakan gambar maupun cerita. Bila pada mulanya pembelajaran hanya dilakukan menggunakan kertas dan gambar, seiring berkembangnya zaman muncullah teknologi - teknologi yang dapat menjadi solusi untuk pengajaran geometri yang lebih konkret, seperti; software Neotrie $V R, D G E$ dan Logo serta perangkat keras seperti; komputer, VR, tablet layar sentuh. Sehingga anak akan memiliki gambaran lebih jelas terkait dengan bentuk - bentuk geometri yang akan dipelajari. Selain itu, penggunaan teknologi juga dapat meningkatkan kreatifitas anak untuk berkreasi dengan bentuk - bentuk geometri.

\section{DAFTAR PUSTAKA}

ASLAN, Cengiz. (2017). "Eurasian Journal of Educational Research." Eurasian Journal of Educational Research 69:37.

Crompton, Helen, Melva R. Grant, and Khitam Y. H. Shraim. (2018). "Technologies to Enhance and Extend Children's Understanding of Geometry: A Configurative Thematic Synthesis of the Literature." Educational Technology and Society 21(1):59-69.

Galitskaya, Viktoriya N., and Athanasios S. Drigas. (2020). "Special Education : Teaching Geometry with ICTs Children with Visual Disability." 15(6):173-83.

Özçakır, Bilal, Ahmet Sami Konca, and Nihat Arikan. (2019). "Children'; Geometric Understanding through Digital Activities: The Case of Basic Geometric Shapes." International Journal of Progressive Education 15(3):108-22.

Rodr, L. (2020). "Geometry Teaching Experience in Virtual Reality with NeoTrie VR Geometry Teaching Experience in Virtual Reality with NeoTrie VR." (February).

Zilkova, Katarina. (2017). "Understanding of Selected Geometric Concepts by Pupils of Pre-Primary and Primary Level Education." (October). 